\title{
Students Helping Students: Creating and Evaluating a Collaborative Service Model in the Library
}

\section{Theresa Westbrock and Angie Cox}

\begin{abstract}
This study identifies the successes and challenges associated with the addition of a nonlibrary service desk in a university library's learning commons. The authors wanted to know whether a training and service collaboration with an outside unit could reliably and efficiently connect students to the librarians, academic support services, and other resources that they need; and if advanced skills (including information literacy) training could be successfully built into the existing infrastructure of academic support departments. The authors identified strategies to address barriers when maintaining and improving a collaborative relationship and a dual-desk service model.
\end{abstract}

\section{Introduction}

Many collaborative partnerships between libraries and other academic departments result from growth, usually part of a renovation project or other funding opportunity. This research aims to showcase a model of successful partnership built during a budget and workforce reduction and identify potential barriers to success. As higher education continues to face funding challenges, libraries must have models to remain nimble in the face of potential budget and staff reductions. By integrating other academic services into the library's space and existing service models, libraries and their partners can continue to offer a variety of high-quality services, sustain their specific missions, and build foundations for future collaborative planning. This study was directly guided by Academic Library Impact: Improving Practice and Essential Areas to Research, ${ }^{1}$ a report that outlines ways for libraries to focus on student success and better communicate their value to stakeholders. The report builds on the Association of College and Research Libraries' well-established Value of Academic Libraries initiative. This study aims to address the report's Collaborate with Educational Stakeholders priority area question, "How can library administrators and staff collaborate with staff and faculty from other academic departments within the same academic institution to increase student learning and success?"

\footnotetext{
*Theresa Westbrock is Associate University Librarian and Associate Professor, Library, and Angie Cox is Library Instruction Coordinator and Assistant Professor, Library, both at the University of Northern Iowa; email: theresa. westbrock@uni.edu, angela.cox@uni.edu. This project was supported by an Academic Library Impact Research Grant from ACRL's Value of Academic Libraries committee. (2020 Theresa Westbrock and Angie Cox, AttributionNonCommercial (https://creativecommons.org/licenses/by-nc/4.0/) CC BY-NC.
} 


\section{Background}

Rod Library is at the center of the University of Northern Iowa, a regional comprehensive university with just over 10,000 students. The library's popularity and central location make it highly valued real estate on campus. Its rooms and spaces are commonly used for campus events, lectures, presentations, and small conferences. Thus, the library has created many space partnerships to the benefit of both parties. Leading up to the partnership at the center of this study, the library already had space partnerships with School Library Studies, a program administered through the College of Education; the UNI Museum, which moved into the library and became a unit of the library in 2012; the Digital Media Hub, an office of centralized IT services; the Center for Excellence in Teaching and Learning, administered through the Office of the Provost; and Undergraduate Studies, also administered through the Office of the Provost.

Ideally, partnerships are made with care, strategic thought, and an eye toward long-term planning. When dedicating resources to a collaboration, it needs to be done with forethought: It is easy to give away space; it is much more complicated to take it back. However, partnerships are, at times, thrust together by external forces or decisions. Undergraduate Studies, administered through the Office of the Provost, has been housed in the library for several years. In 2018, they were in the process of restructuring, including taking over the administration of campus tutoring and supplemental instruction to better align student academic success initiatives and services on campus, when they approached library administration with a dilemma. To accommodate their growing services, either they needed more space in the library or they would have to move all of their services to another location on campus. At the time, the library was one year into a merged desk environment, which combined Reference Services with Access Services into the Library Services Desk (LSD), leaving the large, centrally located reference desk on the main floor vacant. Giving prime real estate to an outside department would require building a purposeful and strategic partnership from the start. While the library was amenable to offering the former reference desk to Undergraduate Studies, we realized that giving prime real estate would require building a purposeful and strategic partnership from the start.

The addition of a new and highly visible service point that would likely receive much library traffic would require ongoing assessment of service provision at each of the two service desks (see image 1 below). A dedicated and collaborative partnership prioritizing a training program that promoted a strong referral system was essential for success. Prior to this partnership, Undergraduate Studies did not have a service desk and they were not located in a high trafficked area of the library. Their move to the main floor of the library and to a much more visible location would introduce a major change to their service model.

Through the support provided by an ACRL Academic Library Impact Research Grant, the library built an assessment project to measure the potential success of this nascent partnership. For this study, the authors wanted to know: 1) Can a training and service collaboration with TLC reliably and efficiently connect students to the librarians, academic support services, and other resources that they need? and 2) How, if at all, can advanced skills (including information literacy) training be successfully built into the existing infrastructure of academic support departments, including TLC and LSD, to the academic benefit of student assistants providing services?

To prepare for the move to the main floor of the library and to prepare for staffing a highly visible service desk, the Office of Undergraduate Studies branded their combined services as 
The Learning Center @ Rod Library (TLC) and worked closely with the library to establish areas of collaboration including training for TLC student assistants and LSD student assistants on basic skills (job-related) and advanced skills (supplemental skills, such as information literacy, communication, and other essential skills) for the purpose of staffing the two desks with a common service model; dedicated space in the library's Learning Commons for peer mentors and tutors to conduct office hours; and a redefined cross-disciplinary service desk in the library's Learning Commons staffed by TLC students. In addition, TLC offered online and drop-in tutoring with a writing center as well as math and science tutors; academic coaching; peer mentoring; supplemental instruction for historically difficult courses; and supportive seminars focusing on topics such as time management and test taking.

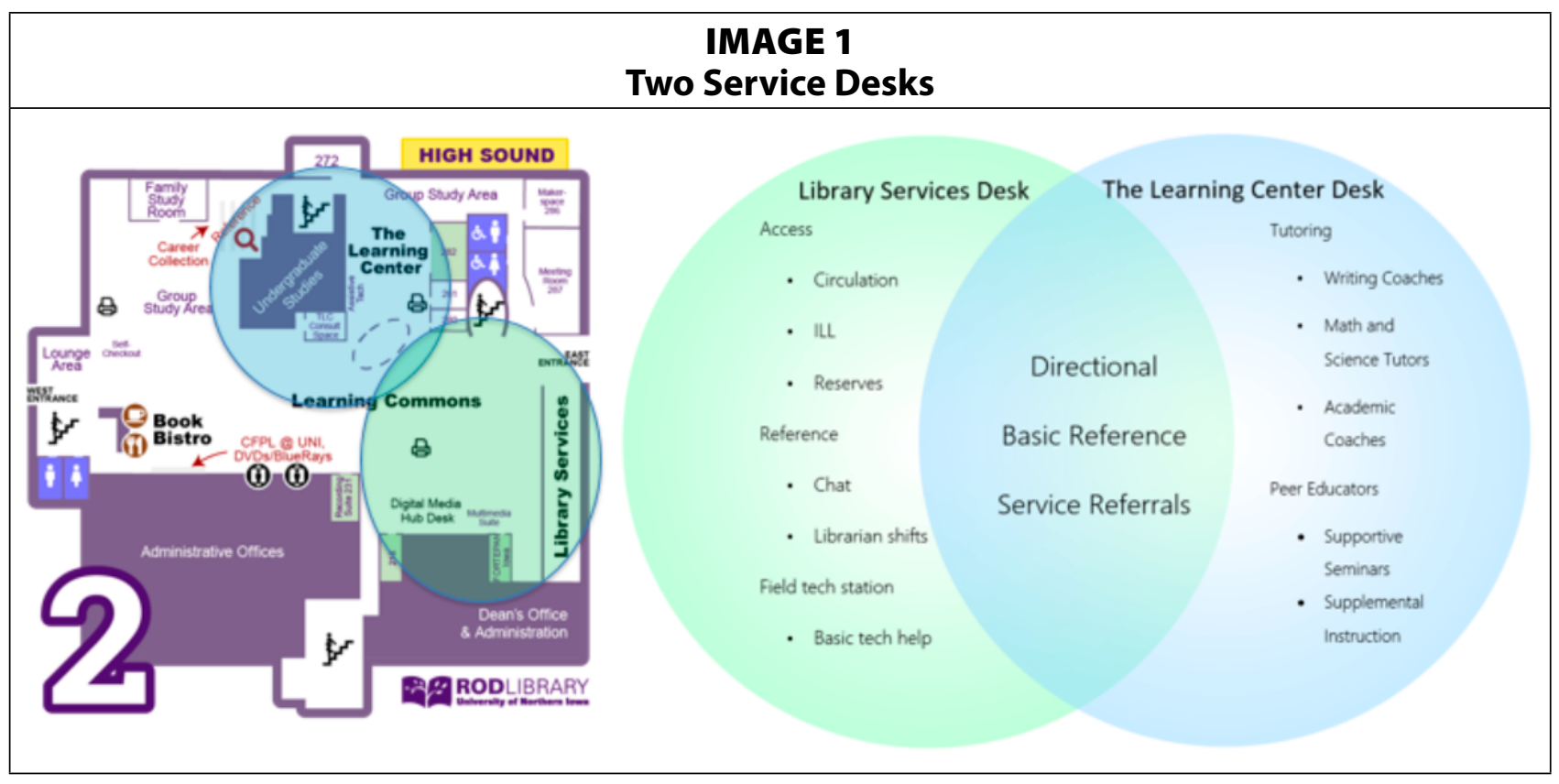

\section{Literature Review}

While the relationship outlined in this study is collaborative, it is important to note that neither party was looking to modify any of its services or change who offered each service. Rather, they sought to maintain a high level of service to students by establishing a base of knowledge to be shared strategically and intentionally. Therefore, this review of literature is twofold: library student assistant training and the role of referrals in libraries.

In this study, the scope of student assistant training is limited to exploring advantages and challenges to advanced training, students' perspectives on training, and motivating and engaging students in the training process. Training student assistants to staff a service desk provides many advantages to the library, the student employee, and the library patron. Training student assistants to answer basic questions and support a strong referral system frees librarians from sitting at the reference desk and allows librarians to work on more complex research inquiries. For the student employee, it also provides peer leadership opportunities. ${ }^{2}$ It aids the student assistant in their own studies, strengthening their information literacy skills and increasing their awareness of the library resources and services. ${ }^{3}$ Heather Jacobson and Kristen Shuyler found that 80 percent of student workers in their study said working in the library made them "more comfortable using the library services, resources, and spaces 
for their own studies." ${ }^{4}$ Erin McCoy found that library student employees graduated with a higher average GPA than that of their fellow graduates. ${ }^{5}$ There are also advantages for all library users. Training student assistants allows libraries to stay open later and maintain ready reference services despite limited availability of librarians. Sandy Farrell and Carol Driver state that students who use the library "tend to relate more easily to the student assistants than to the regular library staff" - which could increase the likelihood that our users would seek library assistance. ${ }^{6}$

There are challenges to training student assistants. It takes a large amount of staff time to train students, an issue that is exacerbated by a high turnover rate. ${ }^{7}$ Jane Kathman and Michael Kathman list a number of additional challenges to training student employees: student supervisors have other job duties in addition to training student employees so availability to spend time training is limited; there may be a large number of students to train at one time due to students' part-time status and high turnover rate; and training needs to be completed in a short period of time, often before the first day of classes. Student training programs continually need to be evaluated and revised. ${ }^{8}$ Library staff who create student training programs must prepare students to function without supervision. ${ }^{9}$ Being a more transient group of employees, the level of engagement is also an area of concern. Farrell and Driver state that "students do not view the job as a 'real' job, but as a stepping stone to their chosen occupation."10

To date, most research in the library literature related to student training is written from the perspective of the library, but little research exists about the student perspective. ${ }^{11}$ Jacobson and Shuyler found that students tended to view their "library employment as having a positive effect on their academic performance." ${ }^{12}$ Students also reported that they found the transferable skills and work experience gained in the library to be valuable whether or not they intended to pursue a career in libraries. ${ }^{13} \mathrm{McCoy}$ found that 82 percent of student employee participants felt that working in a library "increased their academic success." ${ }^{14}$ Andrew Brenza, Michelle Kowalsky, and Denise Brush found 43 percent of student participants stated their library training would be quite useful to them in their coursework, while 57 percent of participants said that the library training would help them "some" in their coursework. ${ }^{15}$ In a study by Amanda Melilli, Rosan Mitola, and Amy Hunsaker, students found "value in skills that are transferable to multiple areas of their lives." ${ }^{16}$ Student employee participants (97\%) found what they learned in the library workshop was useful for their academic studies. A slightly smaller percentage (a rate above $80 \%$ ) of participants also agreed with "the statements that library skills provided skills for jobs after college and life outside of work and school."17

Whether or not a student employee finds value in their library job, the skills they acquire while engaging with the work are valuable. Therefore, motivation and engagement are relevant to the discussion of student employees in an academic library. Michelle Reale argues that "motivation is a muscle that must be developed."18 It is something that can change over time and something that employers can foster ${ }^{19}$ Terrence Luther Cottrell and Brigitte Bell state that students are capable of offering high-quality service if they are "properly motivated, nurtured and informed of their value as essential library employees." ${ }^{20}$ This begins early on when students first begin working for the library. Employers should set clear expectations and model these behaviors. ${ }^{21}$ Some researchers emphasized the importance of communication in motivating and engaging student employees. ${ }^{22}$ Many argue that, if employers communicate how the student's work fits into the larger mission and vision of the library, student employees are more likely to be engaged in their work..$^{23}$ Sara Smith and Quinn Galbraith reported that, 
since "doing something meaningful or contributing to the library" was one of the top factors keeping students working at the library, employers should capitalize on this value "by helping their Millennial employees understand the importance of their job. Supervisors can explain how an employee's specific job contributes to the library as a whole." 24

For the purpose of this project, referrals were the foundation of the shared service model and were therefore the foundational focus of the shared student training. Referrals have been a key part of reference services ever since nonlibrarians began staffing reference desks. In the late 1960s, it was still relatively uncommon to staff a reference desk with nonlibrarians. A survey of the 54 largest academic libraries in the United States in 1969 showed that only 55 percent of them used nonprofessionals on the reference desk and only 41 percent had nonprofessionals working alone at certain hours. ${ }^{25}$ However, many libraries were beginning to recognize that librarians were spending a considerable amount of time answering nonreference questions. Driven by the desire to free librarians from this "burden of superficial work," 26 as well as the realities of budgetary constraints, expanded service hours, and user expectations, libraries began experimenting with new desk and staffing models. ${ }^{27}$

Although popularized in the 1990s as the Brandeis model, a tiered model of reference essentially began as soon as nonlibrarians began working at reference desks. Experiments with using students at reference desks began in the late 1960s. It quickly became clear that using students in a tiered model of providing reference services worked. An early experiment with a student at the reference desk at SUNY in 1970 found additional positive results, noting that "some students were able to relate more effectively to a peer than to a professional." 28 Although there was general skepticism about allowing students to work at the reference desk, the fact that students could "sort" the queries before engaging librarians' time would ultimately allow librarians to assist more users. ${ }^{29}$ The discussion in the literature then shifted to appropriate training methods and to the benefits and challenges of employing students.

A reliable referral procedure is essential to the information desk model: "...with better resource utilization by having senior staff and librarians spend more time answering in-depth research questions rather than directing students to photocopiers and bathrooms." ${ }^{30}$ If librarians are not physically present at the desk to assist a patron seeking research assistance, they need a reliable way to connect with the patron. From the beginning, "special attention" has been given to the referral procedure. In Arthur Young's experiment at SUNY, "all research questions and inquiries taking over ten minutes were to be transferred to a professional," reserving referrals for difficult or extensive questions. ${ }^{31}$ Learning when to refer requires considering the categorization of functions taking place at the reference desk. In 1970, those functions were broadly separated into two areas: routine and professional. ${ }^{32}$ Training students to categorize questions is an ongoing challenge, especially as the parameters of routine and professional continually shift.

While in-depth research questions are referred to librarians for research appointments, many ready reference or basic research queries can be answered or mediated by the student workers. The challenge is to train the student workers to determine what is being asked by the patron, how to find that information, and when they should refer the question. ${ }^{33}$

The transition from the reference model (staffed primarily by librarians) to the information desk model (featuring tiered service and relying on referrals) eventually overlapped with the creation of learning commons areas in libraries. ${ }^{34}$ While the information desk model often reduces the number of service desks in the library, learning commons models sometimes end 
up introducing new services and, therefore, new service desks into the library. Each desk provides access to a specific area of expertise, so it is worthwhile considering the cross-training that might be desired to accompany a robust and reliable referral system in a learning commons environment with multiple service desks.

There is little research that outlines the role of referrals in a learning commons model, specifically when service desks are staffed by students and staff from nonlibrary departments. Many models outline services that function independently from one another. But the complete independent function is not realistic in a building with a variety of services. Andrea Stanfield and Russell Palmer note, "Because this model is rapidly growing and becoming accepted in university libraries, students and other staff members are often in a physical location where handling reference question[s] cannot be avoided." ${ }^{35}$ Even with more than one service desk, a patron should be able to approach a desk and receive a basic level of assistance and, if needed, a direct referral. Can referral models work in library spaces that offer a large array of student services, beyond library services? One successful model is able to "provide one-stop service for library users" and "expedite referrals to qualified personnel." ${ }^{36}$

Ultimately, libraries have invited collaborators into their spaces, and they have revised the services offered in these spaces. There is no indication that library spaces will stop evolving. On the contrary, as higher education continues to adapt to enrollment and budgetary realities, libraries will remain relevant by continuing to be flexible in providing information, spaces, and services that meet the needs of their patrons. In these shared spaces "a cross-training approach that brings together multiple campus units may help break down the 'silos' that form at large academic institutions, lead to more accurate referrals, and facilitate a more seamless experience for students." ${ }^{137}$ For this study, the authors wanted to explore the reliability and efficiency of training and service collaborations with TLC and whether or not advanced skill training could be successfully built into the existing infrastructure of the departments.

\section{Methodology}

This study gathered data in two different ways: transactional data and interviews. To explore the nature of users' needs and whether the users were being connected to the services they needed, transactional statistics were collected at TLC and LSD service desks via a short online form. Transactional data was collected during the 2018-2019 academic year. For this study, transactional data from the first month of the semester was used. Transactional data was collected at each desk through an online form created in LibInsight, a Springshare product. Data was collected through three questions on the form: question type, where did question get referred to, and describe technology questions whether they were referred or not. Question type options were directional, reference, technology help, referral, or "other."

To investigate the perceived effectiveness of the referral process and whether advanced skills training for student assistants could be successfully built into the existing infrastructure of the LSD and TLC service desks, interviews of student assistants (student employees) and student supervisors (professional staff employees and one graduate assistant employee) were conducted. Interviews were conducted in spring 2019 and concluded in late April 2019.

For the one-on-one interviews, two groups of participants were identified: 1) student assistants employed at the TLC and LSD service desks and 2) supervisors of the TLC and LSD service desks. Participants were recruited via direct email through an IRB-approved process. Existing training materials and general expectations were reviewed to create two sets of in- 
terview questions. Two different sets of interview questions were created for each participant group (that is, student assistants and student supervisors). Each set of questions (see the appendix) consisted of eight and nine questions (student assistants and student supervisors respectively) including questions about referrals, training, and attitudes.

Transactional statistics from each desk were collected to compare what types of questions were being asked at each desk and the volume of questions referred to other services. Questions were categorized as directional, reference, tech help, TLC services, referral, and other.

Interview data was analyzed using thematic content analysis and sorted by participant type (student assistant or supervisor) and desk type (TLC or LSD). Broad categories were associated with each of the original research questions. One category constructed themes associated with referrals (connecting users to the services they need) and the other category constructed themes associated with training student assistants at a service desk in the library. Researchers identified themes in each category and developed codes. Codes were applied to the interview transcripts to identify similarities and differences in participant responses.

\section{Results}

A total of 15 student assistants (52\% response rate) and seven supervisors ( $88 \%$ response rate) participated in the interviews for a total of 22 participants. Sorted by service desk, a total of 10 LSD student assistants (53\% response rate), five LSD supervisors (83\% response rate), five TLC student assistants (50\% response rate), and two TLC supervisors (100\% response rate) participated in the interviews.

Student assistants from both desks $(n=15)$ showed a consistent understanding of the referral process. All but one described an acceptable basic referral procedure. Supervisors from both desks $(n=7)$ were unanimously confident in the student assistant's use of referrals. Related, student assistants and supervisors agreed that incorrect referrals to their service area happened infrequently and that, when they did happen, the referrals were likely not internal referrals but rather referrals from elsewhere on campus. Importantly, scheduled research consultations increased by 14 percent for the period under review; 30 percent of those sessions were scheduled using LibCal, a Springshare scheduling software, which served as a service desk tool for completing referrals to librarians.

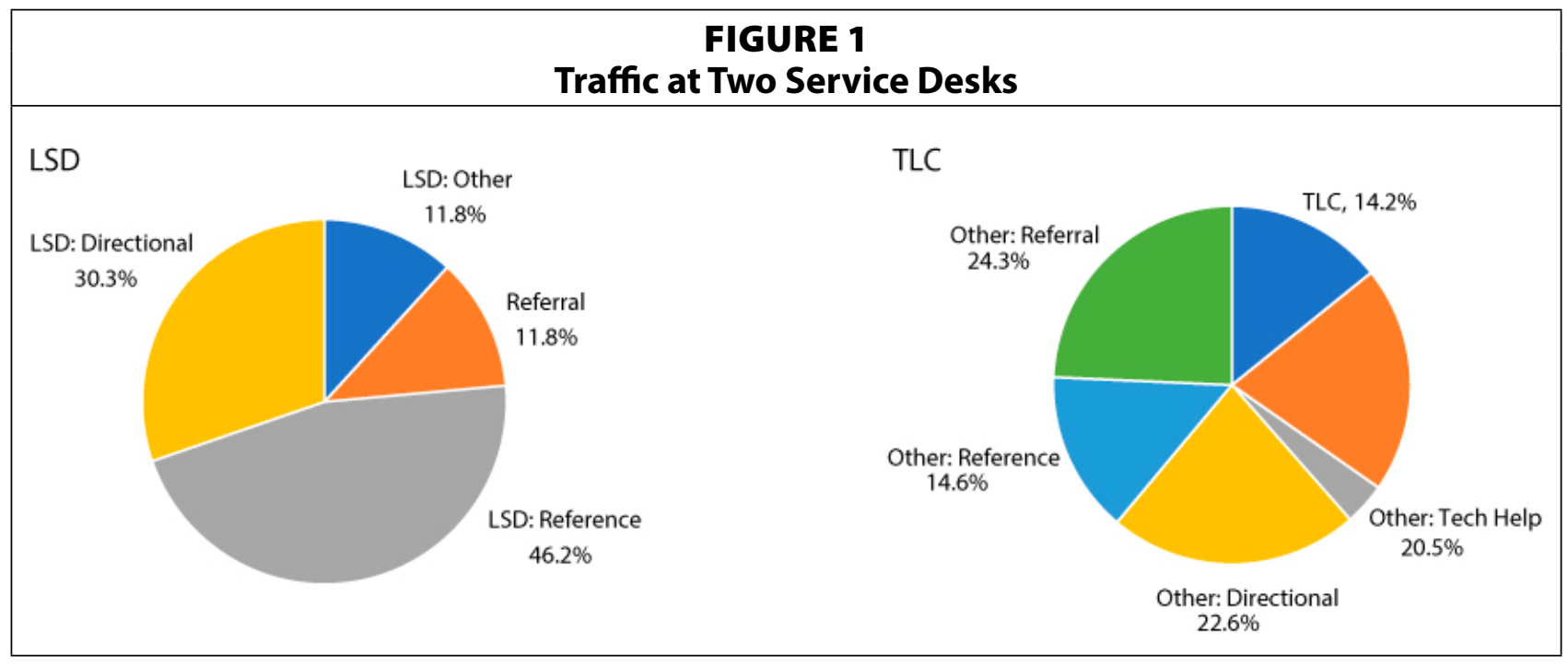


Looking at a sample of transactional statistics from both service desks, TLC handles many more referrals than LSD. Less than a quarter of transactions (24\%) at TLC resulted in a referral, and 60 percent of those referrals were to LSD. On the other hand, only 12 percent of traffic at LSD resulted in a referral, and only 35 percent of those were referrals to TLC. In the case of LSD, all nonreferrals are the expected business of the desk. In other words, 88 percent of LSD desk traffic was appropriate to the desk. In the case of TLC, only 14 percent of desk traffic was within their department's authority (see figure 1). The rest was referrals (24\%), directional (22\%), help with technology $(20 \%)$, and ready reference $(15 \%)$.

Digging deeper into improving referrals, student assistants and supervisors were both asked to identify barriers to complete timely or accurate referrals. There was one common barrier identified: 40 percent of student assistants identified their own lack of knowledge as a barrier and supervisors mostly concurred with them (71\%), also identifying student assistants' lack of knowledge as a barrier. Related, supervisors also commonly identified student assistants' inexperience as a barrier, perhaps confident that more time on the job would naturally eliminate barriers. Only one student assistant identified inexperience as a barrier. Three student assistants (20\%) identified a lack of understanding of the patron's needs as a barrier. This collection of identified barriers found in the interviews can be addressed via ongoing student assistants' training (specific topics, the reference interview, and other training modalities).

Student assistants commonly identified time-related pressure as a barrier when working with patrons. They mention feeling "too busy," "pressured for time," "rushed," and that "the patron is in a hurry." A few others felt overwhelmed by the amount of information they needed to know about the different areas and services in the library. These barriers were not identified at all in the interviews with supervisors (see figure 2). While these barriers might

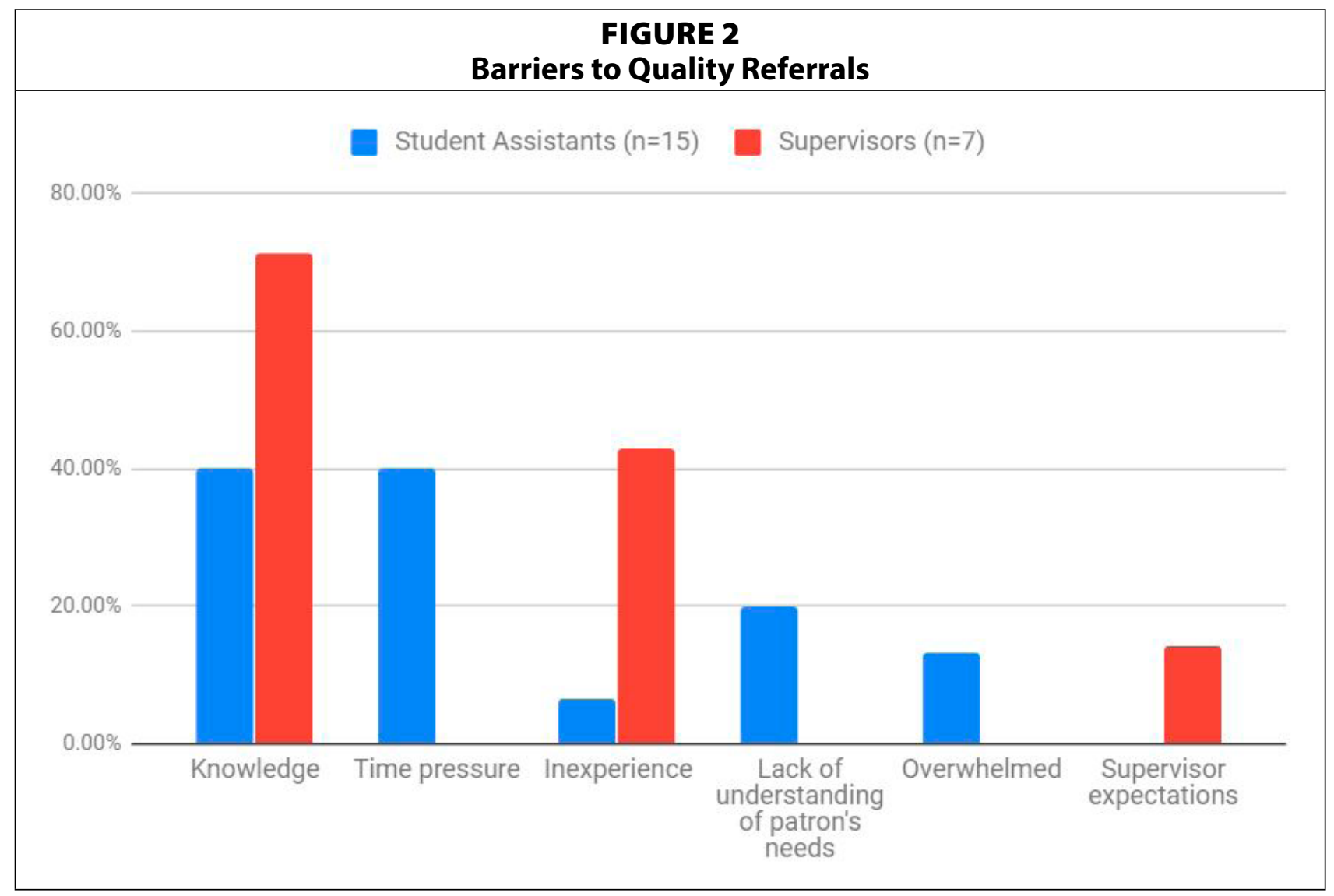


not be able to be addressed directly via training, they might be addressed indirectly through attention to the culture of the workplace at the service desks.

To have a strong referral system in place, student assistants need to be adequately trained to the point where they feel comfortable with their job duties. When asked if there were parts of the reference training that student assistants felt was not directly related to their job, responses were dependent upon which desk they worked. Unanimously, student assistants at LSD found all training to be related to their job. The majority of the student assistants from TLC found the training to be related to their job. Only one TLC student assistant found some of the training relevant but overall felt negative for having to go through training that is not directly useful for their job. Some TLC student assistants (60\%) felt it was helpful information for them as students even though they reported it not being helpful to them as student employees.

In comparison, four supervisors (57\%) think that student assistants are willing to learn things that are not directly related to their job while three supervisors (43\%) said they did not believe student assistants are willing to learn things that are not related to their job. One supervisor noted that, if student assistants are given the intent behind why they are learning something, they will be eager to learn new things regardless if it is for their job or for personal studies. A TLC supervisor noted that they do not think student assistants are willing to learn extra and see a "not my job" mentality with many student assistants where they are not willing to take on more than they have to. Other supervisors who responded negatively to this question also noted that they did not think student assistants were willing to learn things that were not directly related to their job. When asked if they thought student assistants valued the training that is provided to them, there was not a consensus. Three of the student supervisors (43\%) did think student assistants value training while two supervisors $(28.5 \%)$ were unsure if student assistants valued it. Two supervisors (28.5\%) did not think student assistants valued training and stated that they think student assistants resent the "homework" aspect of training, finding it burdensome. Two LSD supervisors (28.5\%) said that student assistants value reference training the most and value circulation training the least. Two TLC supervisors (100\%) said student assistants value coaching and tutoring training the most and value reference training the least.

A majority of the student assistants (87\%) were willing to learn things that were not directly related to their job. Five of the student assistants willing to learn additional things said that the training should be optional. One of the willing student assistants said that, if it was an optional training, most student assistants would not participate in it. The responses of what the additional training should cover varied considerably. The following were some of the responses: style guides, databases, other departments, things related to career or major, help with tutoring, advanced research methods, Special Collections and Archives, and Digital Media Hub equipment. One student assistant said, "Anything!"

Generally, most participants (student assistants and supervisors) felt student assistants should be cross-trained; largely, they noted that training on other desks and departments (such as hours, policies) would be helpful to make a good referral. Three supervisors said that crosstraining would be too much training for student assistants, that they may become overwhelmed. One student assistant noted a sense of separation between the desks and that, while crosstraining is nice in theory, this separation would keep it from being successful. Just over half of the student assistants mentioned an interest in cross-training in different library service areas.

The open-ended question, "Does it make sense to have TLC in the library?" was posed to each interviewee, student and supervisors both, at the end of the interview session. Despite 
concerns about processes, communication, and cross-training, interviewees unanimously agreed that it "makes sense" for TLC to be located in the library. Half mentioned that TLC's services were easier to access in the library than in their former location, which was referred to as out of the way and confusing. The library's space was referred to positively, as welcoming, open, friendly, a hub, a community - all of which benefit partners within the same space. The partnership is seen as a way to keep students in the library, increase traffic, and create a one-stop shop for similar and related services to students. Three interviewees indicated that having TLC in the already-busy, popular library could remove the stigma associated with seeking out tutoring services. Having these services in a place where students already are increased the likelihood that they will be comfortable using them.

\section{Discussion}

Can a training and service collaboration with TLC reliably and efficiently connect students to the librarians, academic support services, and other resources that they need?

Accurate and timely referrals are at the core of Rod Library's service desk model. The researchers are confident that the referral system is fundamentally working, as evidenced by the 14 percent increase in scheduled research consultations, so attention can shift to identifying and addressing barriers to maintaining and improving the collaborative relationship, the dual-desk service model, and basic and advanced training.

Collaborative relationships in libraries require a common goal; and, while there is plenty written about collaborations, there is little that outlines the challenges inherent in collaborations between separate departments. The current study identified some challenges that need to be addressed should a collaboration with outside partners continue to be healthy. The goals of student affairs and libraries overlap, most obviously in that they are both deeply rooted in student success. However, they are of separate philosophies. Where student affairs focuses on educating the "whole" student, putting emphasis on "the development of the student as a person rather than upon his intellectual training alone," 38 libraries focus on information literacy and connecting students to information. This fundamental difference is essential to keep in mind while creating common goals - the existence of a common goal does not and should not ensure that there is a correct pathway to it.

Communication is important in the presence of philosophical and cultural differences. Pauline Swartz, Brian Carlisle, and E. Chisato Uyeki note that "cross-campus collaborations can easily break down due to challenges in communication and misunderstandings due to cultural differences of campus units." ${ }^{39}$ For example, the library regularly collects transactional data of many types, but TLC does not. The library was surprised when TLC transactional data was greatly underreported after just a month of the partnership. However, looking through the lens of departmental cultural difference, transactional data collection was seen by one desk as an assumed practice (and therefore completed) and by the other desk as an extraneous task (and therefore not completed). The only way to combat misunderstandings or gaps in progress is to communicate and be explicit about expectations.

Not surprisingly, many interviewees casually expressed an interest in better or more communication without offering concrete examples for exactly how to improve it. For example, when planning for a student assistant training retreat, it seemed obvious to combine the two groups for a portion of the training. However, neither group was interested in sharing what 
each perceived to be their "own" training session. To maintain cross-training and a base level of core competency among all student assistants, it was essential to explore a better way to encourage both groups to continue working together. Ultimately, "clear and ongoing communication between all parties is essential to the maintenance of partnerships." 40

Many of the identified barriers for providing ongoing quality referrals are intertwined; for example "lack of experience," "time pressure," and "knowledge" are all related. While experience alone can help build knowledge, there are techniques that are likely to support knowledge acquisition and confidence. With an increase in confidence, individual transactions might become more efficient and student assistants may experience a decrease in feeling so much time pressure. Stanfield and Palmer's proposed core competencies, which align with this study's findings, provide an outline for ongoing basic skills training that would likely address the identified barriers that student assistants at the LSD and TLC service desks encounter. They suggest focusing on communication skills, the reference interview, a sense of the collection, the catalog, databases, and technical skills. ${ }^{41}$

How, if at all, can advanced skills (including information literacy) training be successfully built into the existing infrastructure of academic support departments, including TLC and LSD, to the academic benefit of student assistants providing services?

A potential benefit to working in a library setting is the opportunity to acquire advanced skills. However, skills acquisition is reliant on many variables. Simply providing student assistants the opportunity to acquire advanced skills while working in a library setting does not guarantee that student assistants will acquire the skills. Interview data show that student engagement is essential in skills training, especially training for advanced skills that are not required for the job. So, while a low level of engagement can get the basic job done, a high level of engagement is necessary to build advanced skills training into the service desk culture.

Gleaning information from training materials and the interviews of both student assistants and supervisors, "skills" (and associated training) can be separated into two categories. Basic skills are those that are required to be a successful student employee, such as providing accurate referrals, an understanding of services, confidence, and curiosity about other areas and services throughout the library. Basic skills are primarily job-specific and therefore primarily benefit the patrons that the student assistants are serving. A student assistant engaged at a low level in basic skills can still be an effective employee; but, as their engagement increases, their interactions with patrons become more efficient. For example, providing accurate referrals is the basis for a functional service desk, but a student assistant with confidence and curiosity (that is to say, engaged at a higher level) can provide a more complete and efficient referral, require less help from colleagues, and provide patrons with more confidence in the services they are receiving (see image 2).

Advanced skills include any supplemental skills one might obtain as a benefit of working in a library culture, such as information literacy skills, communication skills, and other essential skills. Advanced skills are often not specifically related to the work that student assistants are performing; the primary beneficiary of advanced skills is the student assistant, not necessarily the patrons that the student assistants are serving. A student assistant engaged at a low level in advanced skills is primarily concerned with whether a skill is useful to their job; they might ask, "Do I have to learn this?" As their engagement increases, they will find that the acquisition of advanced skills is useful to their own academic work and experience, exhibiting an appreciation for the academic utility of the skills. Additionally, a student assistant engaged at a high level in advanced skills will find the 


\begin{tabular}{|c|c|c|c|c|}
\hline \multicolumn{5}{|c|}{$\begin{array}{l}\text { IMAGE } 2 \\
\text { Student Engagement and Skills Progression }\end{array}$} \\
\hline $\begin{array}{l}\text { Basic Job Skills } \\
\text { (needed for job) }\end{array}$ & Accurate referrals & Confidence & \multicolumn{2}{|c|}{$\begin{array}{l}\text { Seeks more information, } \\
\text { desires cross-training }\end{array}$} \\
\hline $\begin{array}{l}\text { Advanced Skills } \\
\text { (not needed for job) }\end{array}$ & $\begin{array}{l}\text { Basic utility: } \\
\text { "If it is useful in my job" }\end{array}$ & $\begin{array}{l}\text { Academic utility: } \\
\text { "If it is useful to my own } \\
\text { self as a student" }\end{array}$ & $\begin{array}{l}\text { Academic mat } \\
\text { "If it will be us } \\
\text { myself and oth } \\
\text { throughout my }\end{array}$ & $\begin{array}{l}\text { ity: } \\
\text { l to } \\
\text { s } \\
\text { fe" }\end{array}$ \\
\hline \multicolumn{5}{|c|}{$\rightarrow$ Engagement } \\
\hline \multicolumn{5}{|c|}{$\begin{array}{l}\text { Barriers to engagement: } \\
\text { Willingness } \\
\text { Attitude } \\
\text { Perceived relevance or attitude } \\
\text { Time } \\
\text { Lack of knowledge or experience }\end{array}$} \\
\hline
\end{tabular}

skills useful to their larger lives and are also then able to use it to enhance their interactions with patrons, exhibiting an academic maturity regarding skills acquisition (see image 2).

In both basic skills and advanced skills, the higher levels of engagement are paired with curiosity and self-motivation to learn more. However, there are barriers or limitations that keep student assistants from being more engaged, particularly as it relates to learning skills. This study identified the following barriers to engagement:

- A student assistant's lack of willingness to participate, especially if participation is optional

- A student assistant's negative attitude toward extra training

- The perceived relevance or value of the training opportunity

- Time constraints

- Lack of knowledge and/or experience acquiring advanced skills

The researchers identified a relationship between willingness to participate and relevance/ value particularly as it relates to the level of student engagement. Regarding any training that was supplemental or not technically necessary for a student assistant's job role, there was a positive relationship between their willingness to acquire additional skills to its perceived relevance. If they found a skill to be relevant, they were willing to learn it. This relevance was multifold, though, including relevance to their work, their academics, and their broader life.

\section{Application}

As a direct result of this study, changes and improvements are planned in two general categories: training improvements and barrier reduction.

Training has been improved based on Stanfield and Palmer's core competencies, with special attention to the specific barriers brought up in interviews with student assistants ${ }^{42}$ For example, when student assistants explained why they were unable to provide quality referrals or answer patrons' questions, LSD student assistants generally noted that it was due to their own lack of knowledge or experience, whereas some TLC student assistants suggested that patrons were not clear in what they needed. As a result, basic reference interview training 
was improved, including the addition of interactive reference scenarios. Additionally, training outcomes include any of the following:

- Obtaining general knowledge of the library, spaces, and staff

- Answering directional questions and referring patrons to the appropriate librarian, library staff, or other staff

- Connecting students, faculty, and the community with library services and resources

- Using effective search techniques in databases and other search tools

- Performing reference interviews

- Critically evaluating information and its sources for their value and quality The results of these interviews also provide a basic outline of challenges associated with advanced skills training. In particular, if libraries want student assistants to fully benefit from working in a library culture and to acquire advanced skills, they must be prepared to address barriers to engagement. Recommendations include the following:

- Identifying what advanced skills training should be mandatory and being explicit about the reasons for requiring it, especially in cases where it is not obviously related to the job

- Incentivizing nonmandatory training

- Being prepared to provide adequate time for training

- At regular intervals, inviting suggestions for improvements to training and implementing updates and changes in a timely manner

- In all cases, being explicit about the purpose and benefits of advanced skills acquisition

- Being willing to receive feedback

- Being aware of negative attitudes toward training and addressing them early

Finally, the implementation of a regular and reliable communication plan is essential when working cross-departmentally, because a shared goal does not guarantee a shared path to that goal. So far, this communication plan is operating at three levels. First, support staff members from LSD and TLC work together to create and revise the cross-training materials used by each group's student assistants. Second, a team consisting of designees from each of the library's space partners meets regularly to discuss needs, plans, changes, and other information that might impact their collaborative work. Third, administrators from LSD and TLC have regular informal meetings. These meetings are intentionally free of decision-making; rather, they are intended to build camaraderie.

\section{Conclusion}

The partnership between the library and The Learning Center @ Rod Library is a success. Core student services are consolidated into one location and the area vacated by the merged desk project is full and vibrant. Additionally, students seeking services in the library are being referred appropriately and scheduled immediately. However, if not for this study, the small philosophical differences might have gone unidentified and could have grown. The benefit of an assessment early in a collaboration project is to identify potential problems before they become problems. Collaborative partnerships will continue to be prioritized in libraries, especially those facing budgetary challenges. Ultimately, the true value in this collaborative partnership is not the collaboration but rather the expanded and rich understanding of each other's vocation. This understanding is only possible with a commitment to communication. Digging deeper into new relationships takes time but offers valuable local insight to guide ongoing communication and future decision-making. 


\section{APPENDIX. Interview Questions \\ Student Assistant Interview Questions}

1. A lot of what is expected of students working at the service desks in the library is making referrals. What do you do when you don't know where to refer someone?

a. What are the trickiest questions that you get at your desk?

2. Are there ever times when you or your coworkers feel like you could make a better or more complete referral and aren't able to do so?

a. Why does this happen? (Too busy? Not knowledgeable? Don't understand the question?)

3. In your experience, are people ever referred to your desk incorrectly?

a. Does it happen a lot?

4. Thinking about the different aspects of training, with a supervisor, the training modules, and any other training with coworkers, are there parts of your training that you feel are not directly related to your job? Give an example. How do you feel about this?

5. There are four service desks on the main floor of the library and four more specialized units in the library. Do you think that students at the various service desks should be cross-trained? To what extent?

6. In many ways, working in the library offers numerous opportunities to learn a variety of skills. Are you interested in learning things (related to information and research) that are not directly related to your job? For example, are you interested in learning some more advanced library research skills like using specialized databases (in areas outside your major), learning new citation styles, learning more advanced internet search strategies, and other skills?

a. What things?

b. What is the best way to do this?

7. The TLC desk and services moved to the library last fall, less than a year ago. Do you think it makes sense for TLC to be in the library?

8. For positive answers, follow with: Are there any drawbacks or other problems you've noticed regarding TLC being located in the library?

\section{Student Supervisor Interview Questions}

1. Based on your observations, what do students do when they don't know the answer to a question?

2. Are there holes in students' understanding of when to refer? Where are they?

a. What barriers have you observed in students' abilities to make high-quality referrals?

3. Are people ever referred to your desk incorrectly?

a. Does it happen a lot?

4. Do you think that students value the training provided to them? (What do they value the most? What do they value the least?) Please explain.

5. There are four service desks on the main floor of the library and four more specialized units in the library. Do you think that students at the various service desks should be cross-trained? To what extent?

6. Do you think students are willing to learn things (related to information and research) that aren't directly related to their job? For example, learning some more advanced library 
research skills like using specialized databases (in areas outside their major), learning new citation styles, learning more advanced internet search strategies, and other skills.

a. Explain why/why not?

b. What things?

c. What is the best way to do this?

7. The Learning Center desk and services moved to the library last fall, less than a year ago. Do you think it makes sense for TLC to be in the library?

a. For positive answers, follow with: Are there any drawbacks or other problems you've noticed regarding TLC being located in the library?

8. Do you feel like there are any differences in the service philosophies of the Rod Library and The Learning Center?

a. If so, can you explain?

b. If not, how would you describe their common service philosophy?

9. How would you describe the relationship between the library and TLC?

\section{Notes}

1. Association of College and Research Libraries (ACRL), Academic Library Impact: Improving Practice and Essential Areas to Research, prepared by Lynn Silipigni Connaway, William Harvey, Vanessa Kitzie, and Stephanie Mikitish of OCLC Research (Chicago, IL: ACRL, 2017).

2. Julie Mitchell and Nathalie Soini, "Student Involvement for Student Success: Student Staff in the Learning Commons," College \& Research Libraries 75, no. 4 (2014): 595, https://doi.org/10.5860/crl.75.4.590.

3. Mitchell and Soini, "Student Involvement for Student Success"; Heather A. Jacobson and Kristen S. Shuyler, "Student Perceptions of Academic and Social Effects of Working in a University Library," Reference Services Review 41, no. 3 (2013): 547-65, https://doi.org/10.1108/RSR-11-2012-0075; Jane M. Kathman and Michael D. Kathman, "Training Student Employees for Quality Service," Journal of Academic Librarianship 26, no. 3 (2000): 176-82, https://doi.org/10.1016/S0099-1333(00)00096-3. brary."

4. Jacobson and Shuyler, "Student Perceptions of Academic and Social Effects of Working in a University Li-

5. Erin H. McCoy, "Academic Performance among Student Library Employees: How Library Employment Impacts Grade Point Average and Perception of Success," Christian Librarian 54, no. 1 (2011): 3-12, available online at https://digitalcommons.georgefox.edu/cgi/viewcontent.cgi?article=1499\&context=tcl [accessed 29 July 2019].

6. Sandy L. Farrell and Carol Driver, "Tag, You're It: Hiring, Training, and Managing Student Assistants," Community \& Junior College Libraries 16, no. 3 (2010): 185-91, https://doi.org/10.1080/02763915.2010.492746.

7. Jared Andrew Rex and Jennifer L.A. Whelan, "The Undergraduate That Could: Crafting a Collaborative Student Training Program," College \& Undergraduate Libraries 26, no. 1 (2019): 19-34, https://doi.org/10.1080/1069 1316.2018.1535923.

8. Kathman and Kathman, "Training Student Employees for Quality Service."

9. Jamie P. Kohler, "Training Engaged Student Employees: A Small College Library Experience," College $\mathcal{E}$ Undergraduate Libraries 23, no. 4 (2016): 363-80, https://oi.org/10.1080/10691316.2015.1049316.

10. Farrell and Driver, "Tag, You're It."

11. Andrew Brenza, Michelle Kowalsky, and Denise Brush, "Perceptions of Students Working as Library Reference Assistants at a University Library," Reference Services Review 43, no. 4 (2015): 722-36, https://doi.org/10.1108/ RSR-05-2015-0026; Jacobson and Shuyler, "Student Perceptions of Academic and Social Effects of Working in a University Library"; Amanda Melilli, Rosan Mitola, and Amy Hunsaker, "Contributing to the Library Student Employee Experience: Perceptions of a Student Development Program," Journal of Academic Librarianship 42, no. 4 (2016): 430-37, https://doi.org/10.1016/j.acalib.2016.04.005; McCoy, "Academic Performance among Student Library Employees."

12. Jacobson and Shuyler, "Student Perceptions of Academic and Social Effects of Working in a University Library."

13. Jacobson and Shuyler, "Student Perceptions of Academic and Social Effects of Working in a University Library."

14. McCoy, "Academic Performance among Student Library Employees." 
15. Brenza, Kowalsky, and Brush, "Perceptions of Students Working as Library Reference Assistants at a University Library."

16. Melilli, Mitola, and Hunsaker, "Contributing to the Library Student Employee Experience."

17. Melilli, Mitola, and Hunsaker, "Contributing to the Library Student Employee Experience."

18. Michelle Reale, Mentoring and Managing Students in the Academic Library (Chicago, IL: American Library Association, 2013).

19. Miriam L. Matteson and Emily Hankinson, "Getting Off on the Right Foot: Psychological Contracts, Socialization Theory and Library Student Workers," Journal of Academic Librarianship 44, no. 4 (2018): 486-92, https://doi.org/10.1016/j.acalib.2018.05.001.

20. Terrance Luther Cottrell and Brigitte Bell, "Library Savings through Student Labor," The Bottom Line 28, no. 3 (2015): 82-86, https://doi.org/10.1108/BL-05-2015-0006.

21. Rex and Whelan, "The Undergraduate That Could"; Michelle Reale, Mentoring and Managing Students in the Academic Library. (Chicago: American Library Association, 2013).

22. Alberta Davis Comer, "Searching for Solutions: Supervising Student Employees," Journal of Access Services 1, no. 4 (2004): 103-13, https://doi.org/10.1300/J204v01n04_09; Reale, Mentoring and Managing Students in the Academic Library.

23. Rex and Whelan, "The Undergraduate that Could: Crafting a Collaborative Student Training Program," College \& Undergraduate Libraries 26, 1 (2019): 19-34, https://doi.org/10.1080/10691316.2018.1535923; Kathman and Kathman, "Training Student Employees for Quality Service"; Sara D. Smith and Quinn Galbraith, "Motivating Millennials: Improving Practices in Recruiting, Retaining, and Motivating Younger Library Staff," Journal of Academic Librarianship 38, no. 3 (2012): 135-44, https://doi.org/10.1016/j.acalib.2012.02.008; Cottrell and Bell, "Library Savings through Student Labor"; Comer, "Searching for Solutions"; Reale, Mentoring and Managing Students in the Academic Library.

24. Smith and Galbraith, "Motivating Millennials."

25. Phil Hoehn and Jean Hudson, "Who Is at the Reference Desk? Academic Library Staffing Patterns," RQ 8 , no. 4 (1969): 242-44, available online at https://www.jstor.org/stable/pdf/25823473.pdf [accessed 29 July 2019].

26. Hoehn and Hudson, "Who Is at the Reference Desk?"

27. David A. Tyckoson, "Issues and Trends in the Management of Reference Services: A Historical Perspective," Journal of Library Administration 51, no. 3 (2011): 259-78, https://doi.org/10.1080/01930826.2011.556936.

28. Arthur P. Young, "Student Assistants: A Report and a Challenge," RQ 9, no. 4 (1970): 295-297, https://www. jstor.org/stable/pdf/25823881.pdf.

29. William F. Heinlen, “Using Student Assistants in Academic Reference," RQ 15, no. 4 (1976): 323-25, available online at https://www.jstor.org/stable/41354349 [accessed 29 July 2019].

30. Pixey Anne Mosley, "Assessing User Interactions at the Desk Nearest the Front Door," Reference E User Services Quarterly 47, no. 2 (2007): 159-67, https://doi.org/10.5860/rusq.47n2.159.

31. Young, "Student Assistants: A Report and a Challenge."

32. Young, "Student Assistants: A Report and a Challenge."

33. Laura Surtees, "Training to Learn: Developing an Interactive, Collaborative Circulation-Reference Training Program for Student Workers," in ACRL 2019 Conference Proceedings, ed. Dawn M. Mueller (Chicago, IL: ACRL, 2019), 810-18, available online at www.ala.org/acrl/sites/ala.org.acrl/files/content/conferences/confsandpreconfs/2019/TrainingtoLearn.pdf [accessed 29 July 2019].

34. Maria T. Accardi, Memo Cordova, and Kim Leeder, "Reviewing the Library Learning Commons: History, Models, and Perspectives," College \& Undergraduate Libraries 17, no. 2/3 (2010): 310-29, https://doi.org/10.1080/106 91316.2010.481595.

35. Andrea G. Stanfield and Russell L. Palmer, "Peer-ing into the Information Commons: Making the Most of Student Assistants in New Library Spaces," Reference Services Review 38, 4 (2010): 634-46, https://doi. org/10.1108/00907321011090773.

36. Sue Samson and Erling Oelz, "The Academic Library as a Full-Service Information Center," Journal of Academic Librarianship 31, no. 4 (2005): 347-51, https://doi.org/10.1016/j.acalib.2005.04.013.

37. Mitchell and Soini, "Student Involvement for Student Success."

38. Nancy Evans and Robert Reason, "Guiding Principles: A Review and Analysis of Student Affairs Philosophical Statements," Journal of College Student Development 42, no. 4 (2001): 359-77, available online at https://lib. dr.iastate.edu/edu_pubs/22 [accessed 29 July 2019].

39. Pauline S. Swartz, Brian A. Carlisle, and E. Chisato Uyeki, "Libraries and Student Affairs: Partners for Student Success," Reference Services Review 35, no. 1 (2007): 109-22, https://doi.org/10.1108/00907320710729409.

40. Swartz, Carlisle, and Uyeki, "Libraries and Student Affairs."

41. Stanfield and Palmer, "Peer-ing into the Information Commons."

42. Stanfield and Palmer, "Peer-ing into the Information Commons." 